\title{
Comprehensive analysis of excision repair complementation group 1 , glutathione $S$-transferase, thymidylate synthase and uridine diphosphate glucuronosyl transferase 1A1 polymorphisms predictive for treatment outcome in patients with advanced gastric cancer treated with FOLFOX or FOLFIRI
}

\author{
BONG-GUN SEO*, HYUK-CHAN KWON*, SUNG YONG OH, SUEE LEE, \\ SUNG-GUN KIM, SUNG-HYUN KIM, HOON HAN and HYO-JIN KIM
}

\author{
Department of Internal Medicine, Dong-A University College of Medicine, Busan 602-715, Korea
}

Received March 11,2009; Accepted April 30, 2009

DOI: $10.3892 /$ or_00000415

\begin{abstract}
Oxaliplatin and irinotecan have proven effective in the treatment of gastric cancer. We attempted to determine whether single nucleotide polymorphisms in ERCC1, GST, $T S$ and UGTIAl predicted overall survival in gastric cancer patients receiving FOLFOX and/or FOLFIRI chemotherapy. Total genomic DNA was extracted from the whole blood of patients. The PCR-restriction fragment length polymorphism technique was applied in order to detect the known variant sites of ERCC1, GST, TS and UGTIA1. The response rate of FOLFOX $(\mathrm{N}=75)$ was $24 \%$. Grade 3-4 neutropenia and neurotoxicity were observed at frequencies of 34.7 and $16 \%$, respectively. TTP and OS of first-line administration of FOLFOX (N=35) were 3.1 months (95\% CI, 0.1-6.1 months) and 13.9 months (95\% CI, 12.2-15.6 months), respectively. Only the GSTM1 positive genotype exhibited a significantly better time to progression $(\mathrm{P}=0.023)$. However, significant genotypic variation of TS, GST and ERCC1, which was assumed to affect the activity of oxaliplatin, was not observed to affect RR, toxicity and overall survival. The response rate of FOLFIRI $(\mathrm{N}=74)$ was $23 \%$. Grade 3-4 neutropenia and diarrhea were observed in 55.4 and $9.5 \%$ of cases, respectively. TTP and OS of first-line administration of FOLFIRI ( $\mathrm{N}=33)$ was 4.9 months (95\% CI, 3.5-6.4 months) and 19.0 months (95\% CI, 8.5-29.5months). The low expression type (2R/2R,
\end{abstract}

Correspondence to: Dr Hyo-Jin Kim, Department of Internal Medicine, Dong-A University College of Medicine, 3-1 Dongdaeshin-dong, Seo-gu, Busan 602-715, Korea

E-mail: kimhj@dau.ac.kr

*Contributed equally

Key words: excision repair complementationgroup 1, elutathione $S$-transferase, thymidylate synthase, uridine diphosphate glucuronosyl transferase 1Al, gastric cancer, FOLFOX, FOLFIRI
$2 \mathrm{R} / 3 \mathrm{C}$ and $3 \mathrm{C} / 3 \mathrm{C}$ ) of TS was associated with a high incidence of grade $\geq 3$ neutropenia. However, significant genotypic variation of UGT1A1, which was assumed to affect irinotecan toxicity, was not observed to affect RR, toxicity or survival. In this study, the GSTMI positive genotype evidenced a significantly better time to progression in cases of advanced gastric cancer being treated with FOLFOX. The low expression type $(2 \mathrm{R} / 2 \mathrm{R}, 2 \mathrm{R} / 3 \mathrm{C}$ and $3 \mathrm{C} / 3 \mathrm{C})$ of $\mathrm{TS}$ was associated with a high incidence of grade $\geq 3$ neutropenia in cases of advanced gastric cancer treated with FOLFIRI.

\section{Introduction}

In Korea, gastric cancer is the most common cancer in men, the second most common cancer in women, and the first leading cause of cancer mortality (1), and it remains the second most frequent cause of cancer-related deaths worldwide (2). Although the incidence of gastric cancer has declined over the past three decades, it is frequently diagnosed in locally advanced or metastatic diseases. Therefore, less than $30 \%$ of patients will undergo a curative resection, and approximately $35 \%$ of the patients who do undergo surgery will survive for 5 years (3). Only $10 \%$ of patients with advanced gastric cancer who undergo chemotherapy survive for 2 years (4). Chemotherapy appears to be the only useful tool for the prolongation of survival and the maintenance of quality of life in the advanced gastric cancer.

The FOLFIRI and FOLFOX regimen, which includes bolus/infusional fluorouracil with folic acid modulation and irinotecan or oxaliplatin, has become the most useful first- or second-line treatment for patients with colorectal cancer (5-7). Since 2003, these regimens have been applied to the treatment of advanced gastric cancer.

Oxaliplatin exerts antitumor effects by virtue of its ability to form platinum-DNA adducts. Bulky platinum-DNA adducts are repaired principally by the nucleotide excision repair pathway, in which proteins of the excision repair crosscomplementation 1 (ERCC1), xeroderma pigmentosum 
group D ( $X P D$, also known as ERCC2) and X-ray repair cross-complementing group $(X R C C)$, all perform crucial functions $(8,9)$. ERCC, XPD and XRCC harbor SNPs, which may confer different activities to platinum agents, thus modifying the clinical outcome (10-12). Glutathione S-transferase $\pi 1$ (GSTP1), which is involved in platinum detoxification, also harbors a polymorphism associated with prolonged survival in cisplatin-treated gastric cancer $(13,14)$.

Irinotecan (CPT-11) is a water-soluble chemical derivative of camptothecin. As an inhibitor of topoisomerase I, CPT-11 interferes with DNA replication, resulting in double-strand DNA breaks and cellular death. CPT-11 is active in a broad array of malignancies, including gastric cancer. The liver is the main site at which CPT-11 is converted into its active metabolite, $\mathrm{SN}-38$. This conversion is mediated by human liver carboxyesterase (CES). Oxidative metabolism of CPT-11 and $\mathrm{SN}-38$ is accomplished via the cytochrome $\mathrm{P} 450$ isoforms 3A4 and 3A5 (CYP3A4 and CYP3A5). Uridine diphosphate glucuronosyltransferase 1A1 (UGT1A1) glucoronidates SN-38 to its inactive metabolite, SN-38G. Moreover, the elimination of CPT-11 via efflux transport is mediated by $A B C B 1$ (multidrug resistance protein 1) and $A B C B 2$ (multidrug resistance protein 2) (15). Interestingly, the most significant progress made thus far in irinotecan pharmacogenomics involves the prediction of toxicity. As stated previously, the hepatic isoform 1A1 of UGT is responsible for the glucuronidation and detoxification of SN-38 to its inactive form, SN-38 glucoronide (16).

As a pyrimidine analogue, 5-FU exerts its antitumor effects through anabolism, which is determined by the rate of catabolism. Thus, the genes coding for the key enzymes in 5-FU metabolism may play a pivotal role in the efficacy of 5-FU. Thymidylate synthase (TS) is the target enzyme for 5-FU and catalyzes the methylation of dUMP to dTMP, a crucial process of DNA biosynthesis. The levels of TS expression in tumor tissues are considered to affect the sensitivity of several tumors, including gastric cancer, toward 5-FU-based chemotherapy $(17,18)$. However, the scarcity of tumor tissue, the potential biases of immunohistochemistry and mRNA quantification, and the genetic heterogeneity of clinical tumor tissue limits its clinical applications. By way of contrast, it is substantially easier to obtain DNA isolated from peripheral blood lymphocytes for polymorphism analysis. Genetic polymorphisms constitute an important mechanism influencing gene function. A great many previous studies have shown that certain TS polymorphisms may affect the response to 5-FU. The first detected functional polymorphism in the TS promoter is a variable number of tandem repeats with two or three repeats of a 28-base pair sequence in the 5-untranslated region (UTR) $(2 R / 3 R)$. The $3 \mathrm{R}$ allele was associated with enhanced TS expression when compared with the $2 \mathrm{R}$ allele $(19,20)$. Another important TS polymorphism is a 6-bp deletion or insertion (del6/ins6) in the 3-UTR. The results of several studies appear to verify that the TS 3-UTR del6 allele is associated with reduced TS mRNA stability and lower intratumoral TS expression, as compared to the ins6 allele (21).

This exploratory pharmacogenomic collateral study was conducted to determine the predictive or prognostic value of germline polymorphisms of candidate genes associated with 5-FU and oxaliplatin/irinotecan.

\section{Patients and methods}

Patients. Patients with metastatic or relapsed AGC were enrolled in this clinical trial. The eligibility criteria included the following: i) pathologically confirmed gastric adenocarcinoma with a measurable lesion; ii) no prior history of other cancer; iii) ECOG performance 0-2; iv) Adequate bone marrow function (absolute neutrophil count (ANC) $\geq 1500 \times 10^{3 /}$ $\mu 1$, platelet count $\geq 100000 \times 10^{3} / \mu 1$ ), renal functions (serum creatinine $\leq 1.5 \mathrm{mg} / \mathrm{dl}$ or calculated creatinine clearance by Cockroft formula $\geq 50 \mathrm{ml} / \mathrm{min}$ ), and hepatic function (aspartate aminotransferase, alanine aminotransferase $\leq 3 \mathrm{x}$ upper limits of normal, total bilirubin $\leq 1.5 \mathrm{x}$ upper limits of normal).

\section{Treatment protocol}

Modified-FOLFOX regimen. On day 1, oxaliplatin (85 mg/ $\mathrm{m}^{2}$ ) was administered via intravenous (i.v.) infusion in $500 \mathrm{ml}$ of normal saline or dextrose over $2 \mathrm{~h}$. On days 1 and 2 , ldLV $\left(20 \mathrm{mg} / \mathrm{m}^{2}\right)$ was administered as an i.v. bolus, immediately followed by 5 -FU $\left(400 \mathrm{mg} / \mathrm{m}^{2}\right)$ administered as a 10 -min i.v. bolus, followed by $5-\mathrm{FU}\left(600 \mathrm{mg} / \mathrm{m}^{2}\right)$ as a continuous $22-\mathrm{h}$ infusion, with a light shield.

Modified-FOLFIRI regimen. On day 1, irinotecan $\left(150 \mathrm{mg} / \mathrm{m}^{2}\right)$ was administered via intravenous (i.v.) infusion in $500 \mathrm{ml}$ of normal saline or dextrose over $2 \mathrm{~h}$. On days 1 and 2 , ldLV $\left(20 \mathrm{mg} / \mathrm{m}^{2}\right)$ was administered as an i.v. bolus, immediately followed by 5 -FU $\left(400 \mathrm{mg} / \mathrm{m}^{2}\right)$ administered as a 10 -min i.v. bolus, followed by $5-\mathrm{FU}\left(600 \mathrm{mg} / \mathrm{m}^{2}\right)$ as a continuous $22-\mathrm{h}$ infusion, with a light shield. Each cycle of chemotherapy was administered every 2 weeks.

Dose modification for toxicity. Dose modifications of oxaliplatin, irinotecan or 5-FU were made for hematologic or gastrointestinal toxicities based on the most severe grade of toxicity occurring during the previous cycle. The patients were evaluated prior to the initiation of each 2-week cycle, using the National Cancer Institute-Common Toxicity Criteria (NCI-CTC). Treatment was delayed for up to one week if symptomatic toxicity persisted, if the absolute neutrophil numbers were $<1500 \times 10^{3} / \mu 1$, or if the platelet counts were $<100000 \times 10^{3} / \mu 1$. The dosage of 5 -FU was reduced by $25 \%$ for subsequent courses if NCI-CTC grade 3 stomatitis, dermatitis, thrombocytopenia and neutropenia were noted. The dose of oxaliplatin was also reduced by $25 \%$ in subsequent cycles in cases of NCI-CTC grade 3 neuropathy and neutropenia. The dose of irinotecan was also reduced by $25 \%$ in subsequent cycles in cases of NCI-CTC grade 3 diarrheas and neutropenia. Treatment was continued until signs of disease progression or unacceptable toxic effects developed or until a patient refused further treatment.

Assessment of response. Physical examination, complete blood counts, chemistry and chest X-rays were conducted after each cycle. Responses were assessed using RICIST criteria (22). Computed tomography (CT) scans were repeated every three cycles or earlier in cases of clinical deterioration. Only patients with unidimensionally measurable lesions on the CT scan were evaluated for tumor response. 
Table I. Primer sequences and restriction enzymes.

\begin{tabular}{|c|c|c|c|}
\hline & Gene primers & Enzyme & Refs. \\
\hline \multicolumn{4}{|l|}{ UGT1Al } \\
\hline $\mathrm{U} 1 \mathrm{~F} 1$ & 5'AGATACTGTTGATCCCAGTG3' & Ava II & Huang et al (23) \\
\hline U211R & 5'CTTCAAGGTGTAAAATGGTC3' & & \\
\hline $\mathrm{U} 1 \mathrm{~F} 4$ & 5'CACTGTATTCTTCTTGCATG3' & Bsr I & \\
\hline U1R2 & 5'CGATCCAAAGTAATACATCTG3' & & \\
\hline $\mathrm{U} 4 \mathrm{~F} 4$ & 5'GCCAACATGTCCTACATTGC3' & $\mathrm{Bcl} \mathrm{I}$ & \\
\hline U1091R & 5'GTGATAAAGGCACGGGTGAT3' & & \\
\hline $\mathrm{U} 5 \mathrm{~F} 3$ & 5'GTGGAGTTTGTGATGAGGCA3' & Ava II & \\
\hline U5R1 & 5'GGAAATGACTAGGGAATGGT3' & & \\
\hline (TA)F & 5'TAACTTGGTGTATCGATTGGT3' & & \\
\hline (TA)R & 5'CTTTGCTCCTGCCAGAGGTT3' & & \\
\hline \multicolumn{4}{|l|}{ ERCCl } \\
\hline $118 \mathrm{~F}$ & 5'GCAGAGCTCACCTGAGGAAC3' & HруCH4 & Zhou et al (24) \\
\hline $118 \mathrm{R}$ & 5'GAGGTGCAAGAAGAGGTGGA3' & & \\
\hline $8092 \mathrm{~F}$ & 5'TGAGCCAATTCAGCCACTAGAG3' & Mbo II & \\
\hline $8092 \mathrm{R}$ & 5'CTTTAGTTCCTCAGTTTCCCG3' & & \\
\hline \multicolumn{4}{|l|}{ GST } \\
\hline P1-105F & 5'ACCCCAGGGCTGTATGGGAA3' & Alw261 & Harries et al (25) \\
\hline P1-105R & 5'TGAGGGCACAAGAAGCCCCT3' & & \\
\hline \multicolumn{4}{|l|}{$G S T$} \\
\hline M1F & 5'GAACTCCCTGAAAAGCTAAAGC3' & & Arand et al (26) \\
\hline M1R & 5'GTTGGGCTCAAATATACGGTGG3' & & \\
\hline $\mathrm{T} 1 \mathrm{~F}$ & 5'TTCCTTACTGGTCCTCACATCTC3' & & \\
\hline $\mathrm{T} 1 \mathrm{R}$ & 5'TCACCGGATCATGGCCAGCA3' & & \\
\hline \multicolumn{4}{|l|}{$T S$} \\
\hline TS25F & 5'AGGCGCGCGGAAGGGGTCCT3' & Hae III & Kawakami et al (19) \\
\hline TS18R & 5'TCCGAGCCGGCCACAGGCAT3' & & \\
\hline
\end{tabular}

ERCC1, excision repair complementation group 1; GST, glutathione S-transferase; TS, thymidylate synthase; UGT1A1, uridine diphosphate glucuronosyl transferase $1 \mathrm{~A} 1$.

Genotyping. Total genomic DNA was extracted from $200 \mu 1$ whole blood of AGC patients using a QIAamp DNA Blood Mini kit (Qiagen, Valencia, CA, USA). The PCR-restriction fragment length polymorphism (RFLP) method was applied for the detection of the known variant sites.

After restriction enzyme analysis, the PCR fragments were detected via electrophoresis on 1.5-3.5\% agarose gels. All restriction enzymes were purchased from New England BioLabs (Hertfordshire, UK). Primer sequences, restriction enzymes, and references for the analyses are provided in Table I. An aliquot of $100 \mathrm{ng}$ of total genomic DNA from each sample was utilized as a template in a PCR reaction with $200 \mathrm{ng}$ each of primers, $1.25 \mathrm{mM}$ of each dNTP, buffer solution [10 mM Tris- $\mathrm{HCl}(\mathrm{pH} 8.3), 50 \mathrm{mM} \mathrm{KCl}, 1.5 \mathrm{mM}$ $\mathrm{MgCl}_{2}$ ] and $1 \mathrm{U}$ Taq DNA polymerase (Promega, Madison, USA) in a total volume of $25 \mu 1$. Each PCR reaction condition was as previously described (Fig. 1) (19,23-26).
Statistical methods. The two-tailed $\chi^{2}$ test was conducted to determine the significance of the difference between the covariates. Survival durations were calculated via the Kaplan-Meier method. The log-rank test was employed to compare cumulative survival in the patient groups. In all tests, $\mathrm{P}<0.05$ was the threshold of statistical significance. The SPSS software program (version 15.0; SPSS, Inc., Chicago, IL) was utilized in the analyses.

\section{Results}

Patients characteristics. Our analysis was conducted with 94 enrolled patients. Seventy-five and 74 patients were treated with FOLFOX and FOLFIRI, respectively. Their characteristics are provided in Table II.

Among the FOLFOX treated patients, the male-to-female ratio was 44-31, the median age was 56 years (range, 29-84), 

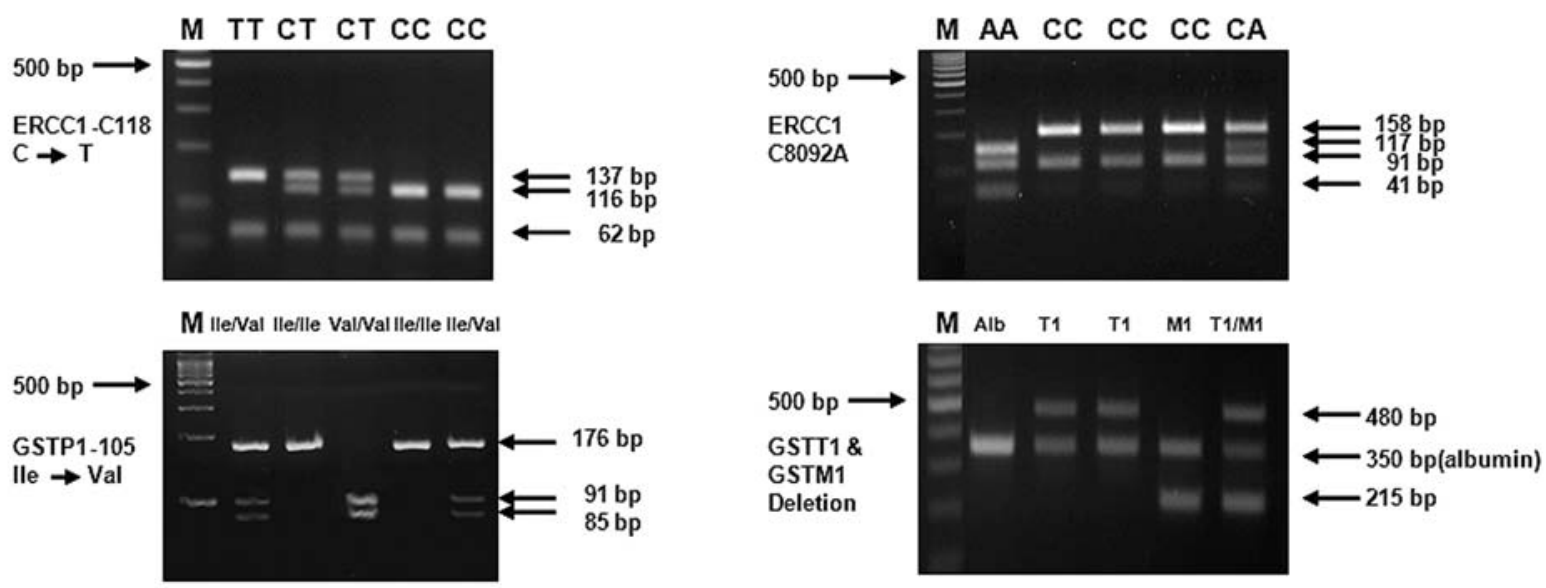

M GA AA GA GG AA
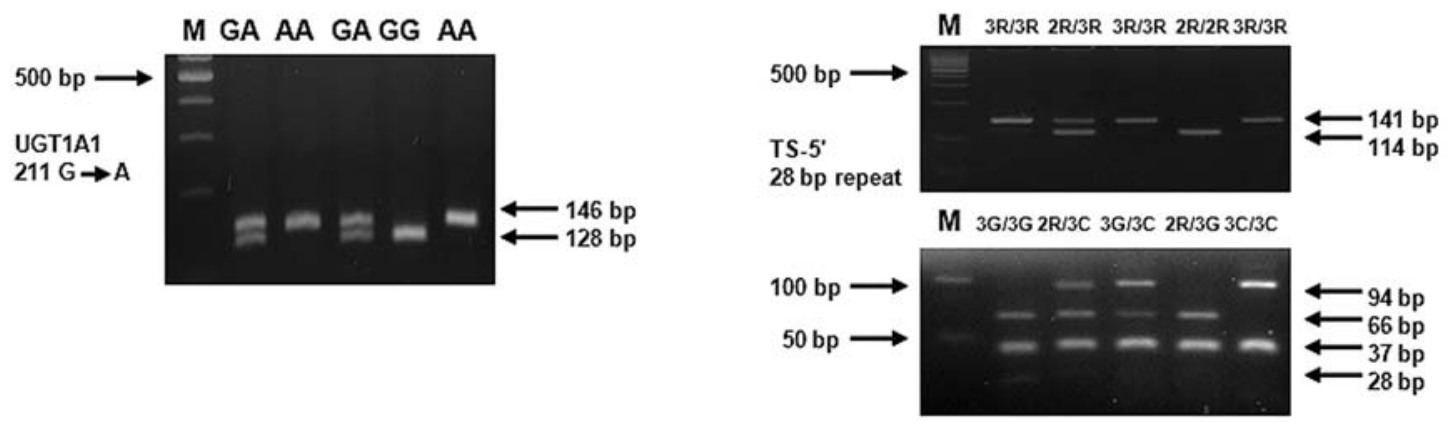

Figure 1. The PCR-restriction fragment length polymorphism (RFLP) method was applied to detect the known variant sites of excision repair complementation group 1 (ERCC1), glutathione S-transferase (GST), thymidylate synthase (TS) and uridine diphosphate glucuronosyltransferase 1A1 (UGT1A1).

$46.7 \%$ were receiving first-line treatment, and $65.3 \%$ of the patients were initially metastatic. Among the FOLFIRItreated patients, the male-to-female ratio was $45-29$, the median age was 54 years (range, 31-84), $44.6 \%$ of patients were receiving first-line treatments, and $65.3 \%$ of patients were initially metastatic.

ERCC1, GST, TS and UGT1A1 genotypes and allele frequencies. We analyzed 7 germline polymorphisms within 4 genes. Among the FOLFOX treatment group, for the ERCC1-C8092A polymorphism, the frequencies of the $C / C$, $C / A$ and $A / A$ genotypes were $52,41.3$ and $6.7 \%$, respectively. For the ERCCl-codon 118 polymorphism, the frequencies of the $C / C, C / T$ and $T / T$ genotype were 56,40 and $4 \%$, respectively. Thirty-nine patients $(52 \%)$ evidenced the GSTT1negative genotype, 49 patients $(65.3 \%)$ GSTM1-negative, and $47(62.7 \%)$ the Ile/Ile and $27(36 \%)$ the Ile/Val genotype of GSTP1. The genotype distributions of the favorable TS genotype $(2 R / 2 R, 2 R / 3 C$ and $3 C / 3 C)$ and unfavorable $T S$ genotype $(2 R / 3 G, 3 C / 3 G$ and $3 G / 3 G)$ were observed in $27(36 \%)$ and $48(64 \%)$, respectively.

With regard to the FOLFIRI treatment group, for the UGT1A1 polymorphism, the UGT1Al variants typed in this study and their allele frequencies are provided in Table III. Forty-four patients $(59.5 \%)$ evidenced the $U G T 1 A 1^{*} 6 G / G$ genotype, 30 patients $(40.5 \%)$ exhibited the $U G T 1 A I^{*} 6 \mathrm{G} / \mathrm{A}$ genotype. UGTIAI*28, UGTIAI*27, UGTIA1*1091 was observed in only 1 patient with a heterozygous allele. The genotype distributions of the favorable $T S$ genotype $(2 R / 2 R$,
$2 R / 3 C$ and $3 C / 3 C)$ and unfavorable $T S$ genotype $(2 R / 3 G$, $3 C / 3 G$ and $3 G / 3 G)$ were noted in $26(35.1 \%)$ and $48(64.9 \%)$ of the subjects, respectively.

Association between ERCC1, GST, TS polymorphism and FOLFOX chemotherapy

Response. In our association analysis of genotype and chemotherapy response, $\mathrm{CR}$ and $\mathrm{PR}$ patients were designated as 'responders' and SD and PD patients were designated as 'non-responders'. The overall rate of response to FOLFOX treatment was $24 \%$. However, different ERCC1, GST and $T S$ genotypes were not correlated with the response rates (Table IV-A).

Toxicity. Toxicities were evaluated using the NCI-CTC v3.0. The major toxicities of FOLFOX treatment were neutropenia and neuropathy. Grade 3 of neutropenia and neuropathy and higher were noted in $26(34.7 \%)$ and 12 (16\%) of the patients, respectively. However, no significant genetic type was observed in conjunction with the ERCC1, GST and TS polymorphisms (Table V-A).

Survival. In order to determine accurately the influence of genetic polymorphism, patients were limited to those who had received FOLFOX as a first-line treatment for advanced gastric cancer. The median TTP and OS values of the firstline administration of FOLFOX $(\mathrm{N}=35)$ were 3.1 months (95\% CI, 0.1-6.1 months) and 13.9 months (95\% CI, 12.215.6 months). 
Table II. Patient characteristics.

\begin{tabular}{|c|c|c|}
\hline & FOLFOX $(\%)$ & FOLFIRI (\%) \\
\hline Total no. of patients & 75 & 74 \\
\hline \multicolumn{3}{|l|}{ Gender } \\
\hline Male & $44(58.7)$ & $45(60.8)$ \\
\hline Female & $31(41.3)$ & $29(39.2)$ \\
\hline \multicolumn{3}{|l|}{ Age } \\
\hline Median (range) & $56(29-84)$ & $54(31-84)$ \\
\hline \multicolumn{3}{|l|}{ Initial presentation } \\
\hline Relapse & $26(34.7)$ & $28(37.8)$ \\
\hline Initial metastatic & $49(65.3)$ & $46(62.2)$ \\
\hline \multicolumn{3}{|l|}{$\begin{array}{l}\text { No. of prior chemo- } \\
\text { therapy }\end{array}$} \\
\hline 0 & $35(46.7)$ & $33(44.6)$ \\
\hline 1 & $32(42.7)$ & $27(36.5)$ \\
\hline$\geq 2$ & $8(10.6)$ & $14(18.9)$ \\
\hline \multicolumn{3}{|l|}{ No. of treatment cycles } \\
\hline Median (range) & $4(1-18)$ & $5(1-27)$ \\
\hline \multicolumn{3}{|l|}{ Response of treatment } \\
\hline $\mathrm{CR}$ & 0 & 0 \\
\hline PR & $18(24.0)$ & $17(23.0)$ \\
\hline SD & $28(37.3)$ & $28(37.8)$ \\
\hline PD & $26(34.7)$ & $25(33.8)$ \\
\hline NA & $3(4.0)$ & $4(5.4)$ \\
\hline \multicolumn{3}{|l|}{$\begin{array}{l}\text { Survival of first-line } \\
\text { treatment }\end{array}$} \\
\hline No. of patients & 35 & 33 \\
\hline TTP (months, 95\% CI) & $3.1(0.1-6.1)$ & $4.9(3.5-6.4)$ \\
\hline OS (months, 95\% CI) & $13.9(12.2-15.6)$ & $19.0(8.5-29.5)$ \\
\hline
\end{tabular}

Only patients with the GTPMI-positive genotype evidenced longer TTP durations than those with the GPTM1negative genotype ( 3 vs. 9 months, $\mathrm{P}=0.023$ ) (Table VI-A, Fig. 2).
Table IV. A. FOLFOX response according to the genotype.

\begin{tabular}{lllll}
\multicolumn{2}{c}{ Frequency } & \multicolumn{2}{c}{ Responder } \\
$\mathrm{N}=75$ & $(\%)$ & $\mathrm{N}=18$ & $(\%)$ & P-value
\end{tabular}

\section{ERCC1-C8092A}

$\begin{array}{llllll}C / C & 39 & 52.0 & 9 & 23.1 & 0.529\end{array}$

$C / A$ or $A / A$

$\begin{array}{llll}36 & 48.0 & 9 & 25.0\end{array}$

ERCC1-118

$\begin{array}{llllll}C / C & 42 & 56.0 & 11 & 26.2 & 0.412\end{array}$

$C / T$ or $T / T$

$\begin{array}{llll}33 & 44.0 & 7 & 21.2\end{array}$

\section{GSTT1}

Positive

Negative

$\begin{array}{lllll}36 & 48.0 & 10 & 27.8 & 0.321\end{array}$

GSTM1

Positive

Negative

$\begin{array}{lllll}26 & 34.7 & 6 & 23.1 & 0.565\end{array}$

$\begin{array}{llll}49 & 65.3 & 12 & 24.5\end{array}$

GSTP1-105

$\begin{array}{llllll}\text { Ile/Ile } & 47 & 62.7 & 10 & 21.3 & 0.328\end{array}$

Ile/Val, $\mathrm{Val} / \mathrm{Val} \quad 28 \quad 37.3 \quad 8 \quad 28.6$

$T S$

$\begin{array}{llllll}2 R / 2 R, 2 R / 3 C, 3 C / 3 C & 27 & 36.0 & 7 & 25.9 & 0.490\end{array}$ $2 R / 3 G, 3 C / 3 G, 3 G / 3 G \quad 48 \quad 64.0 \quad 11 \quad 22.9$

ERCC1, excision repair complementation group 1; GST, glutathione S-transferase; $T S$, thymidylate synthase.

B. FOLFIRI response according to the genotype $(\mathrm{N}=74)$.

\begin{tabular}{lccccc}
\hline & \multicolumn{3}{c}{ Frequency } & \multicolumn{3}{c}{ Responder } & \\
& $\mathrm{N}=74$ & $(\%)$ & $\mathrm{N}=17$ & $(\%)$ & P-value \\
\hline UGT1A1*6 & & & & & \\
$G / G$ & 44 & 59.5 & 10 & 25.0 & 0.583 \\
$G / A$ & 30 & 40.5 & 7 & 26.1 & \\
$T S$ & & & & & \\
$2 R / 2 R, 2 R / 3 C, 3 C / 3 C$ & 26 & 35.1 & 7 & 26.9 & 0.375 \\
$2 R / 3 G, 3 C / 3 G, 3 G / 3 G$ & 48 & 64.9 & 10 & 20.8 & \\
\hline
\end{tabular}

UGT1A1, uridine diphosphate glucuronosyl transferase 1A1; TS, thymidylate synthase.

Table III. UGT1Al expression in FOLFILI treated patients $(\mathrm{N}=74)$.

\begin{tabular}{|c|c|c|c|c|c|c|c|c|c|c|}
\hline & \multicolumn{2}{|c|}{$U G T 1 A I^{*} 6$} & \multicolumn{2}{|c|}{$U G T 1 A 1^{*} 28$} & \multicolumn{2}{|c|}{$U G T 1 A 1^{*} 27$} & \multicolumn{2}{|c|}{$U G T 1 A^{*} 7$} & \multicolumn{2}{|c|}{ UGT1A1*1091 } \\
\hline & $G / G$ & $G / A$ & $6 / 6$ & $7 / 6$ & $C / C$ & $C / A$ & $T / T$ & $T / G$ & $C / C$ & $C / T$ \\
\hline No. & 44 & 30 & 73 & 1 & 73 & 1 & 74 & 0 & 73 & 1 \\
\hline$(\%)$ & 58.2 & 41.8 & 98.6 & 1.4 & 98.6 & 1.4 & 100 & 0 & 98.6 & 1.4 \\
\hline
\end{tabular}

UGT1A1, uridine diphosphate glucuronosyl transferase 1A1. 
Table V. A. FOLFOX toxicity according to the genotype $(\mathrm{N}=75)$.

\begin{tabular}{|c|c|c|c|c|c|c|c|}
\hline & \multicolumn{3}{|c|}{$\begin{array}{c}\text { Grade } 3-4 \\
\text { neutropenia }\end{array}$} & \multirow[b]{2}{*}{ P-value } & \multicolumn{2}{|c|}{$\begin{array}{l}\text { Grade 3-4 } \\
\text { neuropathy }\end{array}$} & \multirow[b]{2}{*}{ P-value } \\
\hline & $\mathrm{N}$ & $\mathrm{N}$ & $(\%)$ & & $\mathrm{N}$ & $(\%)$ & \\
\hline \multicolumn{8}{|l|}{ ERCC1-C8092A } \\
\hline$C / C$ & 39 & 14 & 36 & 0.504 & 4 & 10 & 0.136 \\
\hline$C / A$ or $A / A$ & 36 & 12 & 33 & & 8 & 22 & \\
\hline \multicolumn{8}{|l|}{ ERCC $1-118$} \\
\hline$C / C$ & 42 & 14 & 33 & 0.487 & 7 & 17 & 0.559 \\
\hline$C / T$ or $T / T$ & 33 & 12 & 36 & & 5 & 15 & \\
\hline \multicolumn{8}{|l|}{ GSTT1 } \\
\hline Positive & 36 & 11 & 31 & 0.318 & 6 & 17 & 0.564 \\
\hline Negative & 39 & 15 & 38 & & 6 & 15 & \\
\hline \multicolumn{8}{|l|}{ GSTMI } \\
\hline Positive & 26 & 9 & 35 & 0.601 & 2 & 7 & 0.135 \\
\hline Negative & 49 & 17 & 35 & & 10 & 20 & \\
\hline \multicolumn{8}{|l|}{ GSTP1-105 } \\
\hline Ile/Ile & 47 & 18 & 38 & 0.274 & 9 & 19 & 0.266 \\
\hline Ile/Val, Val/Val & 28 & 8 & 29 & & 3 & 11 & \\
\hline \multicolumn{8}{|l|}{$T S$} \\
\hline $2 R / 2 R, 2 R / 3 C, 3 C / 3 C$ & 27 & 12 & 44 & 0.140 & 5 & 19 & 0.445 \\
\hline $2 R / 3 G, 3 C / 3 G, 3 G / 3 G$ & 48 & 14 & 29 & & 7 & 15 & \\
\hline
\end{tabular}

$E R C C 1$, excision repair complementation group 1; GST, glutathione S-transferase; $T S$, thymidylate synthase.

B. FOLFIRI toxicity according to the genotype $(\mathrm{N}=74)$.

\begin{tabular}{|c|c|c|c|c|c|c|c|}
\hline & \multicolumn{3}{|c|}{$\begin{array}{c}\text { Grade 3-4 } \\
\text { neutropenia }\end{array}$} & \multirow[b]{2}{*}{ P-value } & \multicolumn{2}{|c|}{$\begin{array}{l}\text { Grade 3-4 } \\
\text { diarrhea }\end{array}$} & \multirow[b]{2}{*}{ P-value } \\
\hline & $\mathrm{N}$ & $\mathrm{N}$ & $(\%)$ & & $\mathrm{N}$ & $(\%)$ & \\
\hline \multicolumn{8}{|l|}{$U G T 1 A 1^{*} 6$} \\
\hline$G / G$ & 44 & 24 & 55 & 0.524 & 5 & 11 & 0.401 \\
\hline$G / A$ & 30 & 17 & 57 & & 2 & 7 & \\
\hline \multicolumn{8}{|l|}{$T S$} \\
\hline $2 R / 2 R, 2 R / 3 C, 3 C / 3 C$ & 26 & 19 & 73 & 0.021 & 3 & 12 & 0.473 \\
\hline $2 R / 3 G, 3 C / 3 G, 3 G / 3 G$ & 48 & 22 & 49 & & 4 & 8 & \\
\hline
\end{tabular}

UGT1A1, uridine diphosphate glucuronosyltransferase $1 \mathrm{~A} 1 ; T S$, thymidylate synthase.

Association between UGT1A1, TS polymorphism and FOLFIRI chemotherapy

Response. The overall response rate of FOLFIRI treatment was $23 \%$. However, unlike UGT1A1, TS genotypes were not correlated with response rate (Table IV-B).

Toxicity. The major toxicities associated with FOLFIRI treatment were neutropenia and diarrhea. Grade 3 of higher of neutropenia and diarrhea were noted in 41 (55.4\%) and 7
(9.5\%) of patients, respectively. Patients with the $T S(2 R / 2 R$, $2 R / 3 C$ and $3 C / 3 C$ ) genotype frequently exhibited grade $\geq 3$ neutropenia. However, no significant genetic type in terms of the UGT1A1, TS polymorphisms (Table V-A) was found to be causative of grade $\geq 3$ diarrhea (Table V-B).

Survival. The median TTP and OS values of first-line administration of FOLFIRI ( $\mathrm{N}=34)$ were 4.9 months (95\% CI, 3.56.4 months) and 19.0 months (95\% CI, 8.5-29.5 months). 
Table VI. A. First-line FOLFOX survival according to the genotype (N=35).

\begin{tabular}{|c|c|c|c|c|c|}
\hline & $\begin{array}{l}\text { Frequency } \\
\qquad \mathrm{N}\end{array}$ & $\begin{array}{c}\text { TTP } \\
\text { Months }\end{array}$ & P-value & $\begin{array}{c}\text { OS } \\
\text { Months }\end{array}$ & P-value \\
\hline \multicolumn{6}{|l|}{ ERCC1-C8092A } \\
\hline$C / C$ & 18 & 2.8 & \multirow[t]{2}{*}{0.489} & 13.9 & \multirow[t]{2}{*}{0.441} \\
\hline$C / A$ or $A / A$ & 17 & 5.2 & & 13.7 & \\
\hline \multicolumn{6}{|l|}{ ERCC1-118 } \\
\hline$C / C$ & 23 & 3.9 & \multirow[t]{2}{*}{0.362} & 14.7 & \multirow[t]{2}{*}{0.323} \\
\hline$C / T$ or $T / T$ & 12 & 1.7 & & 13.7 & \\
\hline \multicolumn{6}{|l|}{ GSTT1 } \\
\hline Positive & 19 & 3.9 & \multirow[t]{2}{*}{0.783} & 13.7 & \multirow[t]{2}{*}{0.229} \\
\hline Negative & 16 & 3.0 & & 20.5 & \\
\hline \multicolumn{6}{|l|}{ GSTMI } \\
\hline Positive & 12 & 9.5 & \multirow[t]{2}{*}{0.023} & \multirow[t]{2}{*}{34.5} & 0.262 \\
\hline Negative & 23 & 3.0 & & & 13.7 \\
\hline \multicolumn{6}{|l|}{ GSTP1-105 } \\
\hline Ile/Ile & 22 & 3.0 & \multirow[t]{2}{*}{0.599} & 13.2 & \multirow[t]{2}{*}{0.669} \\
\hline Ile/Val, Val/Val & 13 & 3.9 & & 13.9 & \\
\hline \multicolumn{6}{|l|}{$T S$} \\
\hline $2 R / 2 R, 2 R / 3 C, 3 C / 3 C$ & 12 & 3.0 & \multirow[t]{2}{*}{0.422} & 10.8 & \multirow[t]{2}{*}{0.492} \\
\hline $2 R / 3 G, 3 C / 3 G, 3 G / 3 G$ & 23 & 3.9 & & 13.9 & \\
\hline
\end{tabular}

$E R C C 1$, excision repair complementation group 1; GST, glutathione S-transferase; $T S$, thymidylate synthase; $T T P$, time to progression; $O S$, overall survival.

B. First-line FOLFIRI survival according to the genotype $(\mathrm{N}=33)$.

\begin{tabular}{|c|c|c|c|c|c|}
\hline & $\begin{array}{c}\text { Frequency } \\
\text { N }\end{array}$ & $\begin{array}{c}\text { TTP } \\
\text { Months }\end{array}$ & $\mathrm{P}$-value & $\begin{array}{c}\text { OS } \\
\text { Months }\end{array}$ & P-value \\
\hline \multicolumn{6}{|l|}{$U G T 1 A 1^{*} 6$} \\
\hline$G / G$ & 20 & 4.9 & 0.945 & 19.0 & 0.579 \\
\hline$G / A$ or $A / A$ & 13 & 5.1 & & NR & \\
\hline \multicolumn{6}{|l|}{$T S$} \\
\hline$R / 2 R, 2 R / 3 C, 3 C / 3 C$ & 14 & 4.7 & 0.896 & 26.6 & 0.250 \\
\hline$R / 3 G, 3 C / 3 G, 3 G / 3 G$ & 19 & 5.0 & & 11.9 & \\
\hline
\end{tabular}

UGT1A1, uridine diphosphate glucuronosyltransferase 1A1; TS, thymidylate synthase; TTP, time to progression; OS, overall survival.

However, no significant genetic type was observed in terms of the UGT1AI and TS polymorphisms (Table VI-B).

\section{Discussion}

In this study, we assessed four common polymorphisms of the ERCC1, GST, TS and UGTIAl genes and assessed their association with response, toxicity and survival in response to FOLFOX or FOLFIRI chemotherapy in gastric cancer patients.
We have demonstrated that the GSTM1 positive genotype was associated with a significantly better time to progression in advanced gastric cancer patients treated with FOLFOX, and a low expression type $(2 R / 2 R, 2 R / 3 C$ and $3 C / 3 C)$ of $T S$ was associated with a high incidence of grade $\geq 3$ neutropenia in advanced gastric cancer treated with FOLFIRI. It remains unclear, however, as to how the effects of ERCC1, GST, TS and $U G T 1 A 1$ genes relate to chemotherapy in cases of gastric cancer. ERCC1 is a highly conserved protein and an essential member of the NER pathway (27). The ERCC1-XPF 


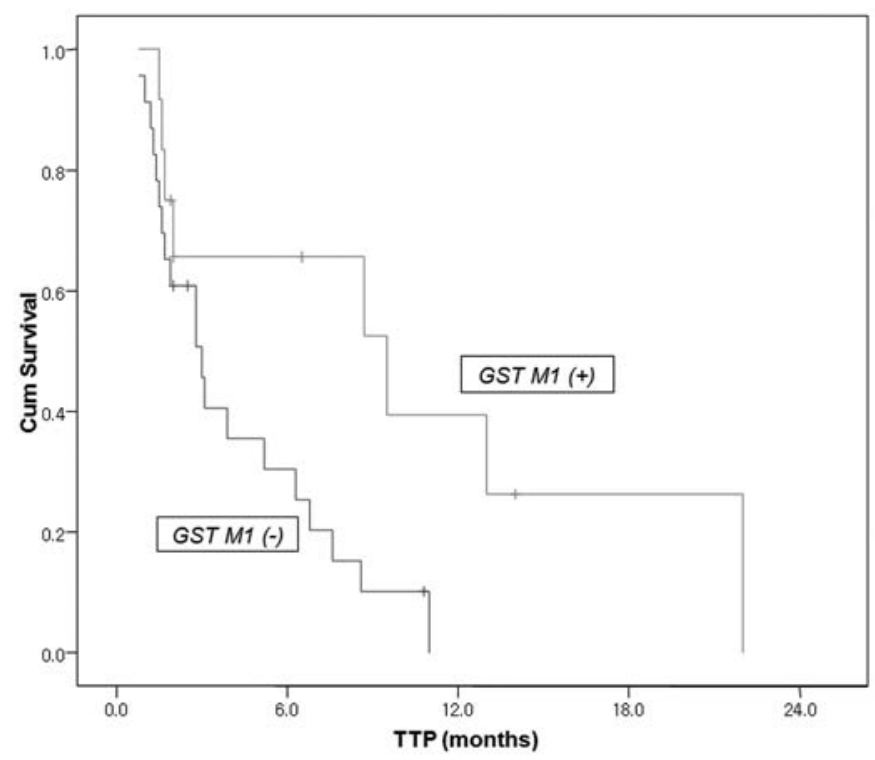

Figure. 2. Glutathione S-transferase (GST) M1-positive genotype showed longer time to progression (TTP) duration than GSTM1-negative (3 vs. 9 months, $\mathrm{P}=0.023)$.

(xeroderma pigmentosum group F) complex is known to be involved in the cleavage of damaged DNA strand 50 to DNA lesions. Several studies have reported an association between the expression of ERCCl and clinical outcomes to platinumbased chemotherapy, including gastrointestinal malignancies $(8,28,29)$. Two common polymorphisms of the ERCCl gene have been identified thus far. The first SNP at codon 118 induces a $\mathrm{C} \rightarrow \mathrm{T}$ change coding for the same amino acid, asparagine, and might affect codon usage. An earlier analysis by Park et al (30), on a small number of patients $(\mathrm{N}=31)$ demonstrated that as the number of $\mathrm{T}$ alleles increased, a trend toward higher intratumoral ERCC1 mRNA was observed. The second ERCCI SNP induces a $\mathrm{C} \rightarrow \mathrm{A}$ change and is located in position 8092 on the 30-UTR. The function of these polymorphisms in platinum sensitivity and toxicity has been retrospectively assessed in a variety of neoplasms, including melanoma $(31)$, lung $(12,24,32)$ and colon $(30,33,34)$ cancers with variable and often contradictory results. Differences in populations, tumor types, therapeutic regimens, and assessments of clinical outcome may have led to diverging results.

However, in the current study, none of the polymorphisms with influence DNA-repair functions from oxaliplatin damage were clearly correlated with clinical outcomes. One possible reason for these controversial findings might be the small sample size of the study. Another salient limitation of this study is that we analyzed only the germ-line genotype. In order to more clearly determine the influence of ERCC1, we also identified the mRNA level and somatic genotype in tumor tissue.

Phase II detoxification enzymes, such as the GSTs, are also believed to be involved in platinum resistance. The GSTP1 isoform is overexpressed in gastrointestinal malignancies, and the results of in vitro studies have demonstrated its significant participation to detoxification and, thus, resistance to platinum agents (35). An SNP substitution of $\mathrm{A} \rightarrow \mathrm{C}$, which causes an Ile $\rightarrow$ Val change at codon 105 , has been associated with a significant reduction in enzymatic activity. Patients with the valine allele were demonstrated to have superior clinical outcomes when receiving oxaliplatin-based chemotherapy for colorectal cancer (36). A recent study has assessed the role of $G S T(P 1, T 1, M 1)$ polymorphisms, as well as polymorphisms of four other genes, as clinical predictors of 5-FU-cisplatin chemotherapy outcomes in cases of advanced gastric cancer. This retrospective study of 52 patients demonstrated that patients homozygous for the GSTP1 valine allele evidenced significantly higher response rates (67 vs. $21 \%$ ) and median survival durations (15 vs. 6 months) (13). Interestingly, a similar pattern was observed in patients with Hodgkin's lymphoma (37) and breast cancer (38) treated with cytotoxic chemotherapy.

In our study, except for the finding that the GSTM1 positive genotype was associated with longer TTP durations in first-line FOLFOX treatment, no associations were detected between the different genotypes of $G S T(P 1, M 1, T 1)$ genes and response, toxicity, and survival.

Consistently with our observation, patients with low drug metabolizing genotypes with acute myeloid leukemia, esophageal cancer, lung cancer, or breast cancer exhibited reduced survival rates in some studies (39-42). This might be attributable to a higher rate of toxicity-related deaths. As all of the patients included in this study received more than $50 \%$ of the projected dose of chemotherapy and no toxicity-related deaths were observed; this fact cannot explain the worse prognosis of the GSTM1-null genotype as observed in our study. The exact mechanisms by which the various GST genotypes affect survival appear to be highly complex, and are not understood in detail.

A common polymorphism of the UGT1Al gene results in an additional TA repeat in the TATA sequence of the UGT1Al promoter, with the longer repeat (7 vs. 6) associated with a significant reduction in SN-38 glucoronidation, potentially resulting in increased toxicity. Up to $33 \%$ of Caucasians harbor the variant allele with seven repeats (43). The ability of the UGTIAl polymorphism to predict severe gastrointestinal and bone marrow toxicity was observed in an earlier study with a small number of patients $(\mathrm{N}=20)$, all of whom had solid tumors and were treated with irinotecan. Patients with the seven TA repeat allele (either $6 / 7$ or $7 / 7$ ) were more likely to experience severe grades of neutropenia and diarrhea (44). Most recently, large-scale prospective pharmacogenetic data from patients with metastatic colorectal cancer treated with irinotecan-based chemotherapy (North Central Cancer Treatment Group N9741) showed that those homozygous for the variant allele (seven repeats) had significantly higher rates of grade 4 neutropenia (36\%) compared with those harboring the more common variant (8.6\%) (45). This has led to an update of the package insert of irinotecan, which warns that patients with the variant UGT1Al polymorphism might be at higher risk for severe neutropenia.

Although several articles have reported a correlation between irinotecan and toxicities, our data did not confirm such a relationship. This might be attributable to differing percentages of the UGTIAl polymorphism (46).

The active metabolites of fluoropyrimidines exert their antitumor activity principally via through $T S$ inhibition. This 
reaction is facilitated by the formation of a ternary complex consisting of TS, 5,10-methylene THF and 5-fluoro-dUMP (47). There is a growing body of evidence to suggest the presence of functionally important polymorphic variations within the TS gene. The 28-bp repeat and the G/C SNP within the 50 UTR of the gene have been demonstrated to alter the expression of TS $(21,48)$. In the current study, patients who possessed a TS 50 genotype associated with low TS mRNA expression levels (49) demonstrated a trend for superior survival time as compared with patients harboring TS genotypes known to be associated with high levels of TS mRNA expression. This observation is consistent with recent findings by Marcuello et al (50) who revealed a significant association between clinical outcomes of 5-FU-based chemotherapy in colorectal cancer and TS polymorphisms only if both TS polymorphisms within the 50 UTR were analyzed in conjunction. A trend between $T S$ polymorphisms and clinical outcomes was noted in gastric cancer patients who received oral fluoropyrimidine therapy (51).

However, in our study, TS polymorphisms did not result in response and survival differences in accordance with genotype. Only the low expression type $(2 \mathrm{R} / 2 \mathrm{R}, 2 \mathrm{R} / 3 \mathrm{C}$ and $3 \mathrm{C} / 3 \mathrm{C}$ ) of TS was associated with a high incidence of grade $\geq 3$ neutropenia.

\section{Acknowledgements}

This study was supported by the Dong-A University Research Fund.

\section{References}

1. Chang JC: Perspectives on stomach cancer. J Korean Med Sci 9: 277-280, 1994

2. Parkin DM, Bray F, Ferlay J and Pisani P: Global cancer statistics, 2002. CA Cancer J Clin 55: 74-108, 2005

3. Cuschieri A, Weeden S, Fielding J, et al: Patient survival after D1 and D2 resections for gastric cancer: long-term results of the MRC randomized surgical trial. Surgical Co-operative Group. Br J Cancer 79: 1522-1530, 1999

4. Schipper DL and Wagener DJ: Chemotherapy of gastric cancer Anticancer Drugs 7: 137-149, 1996.

5. Oh SY, Kwon HC, Lee S, et al: A Phase II study of oxaliplatin with low-dose leucovorin and bolus and continuous infusion 5-fluorouracil (modified FOLFOX-4) for gastric cancer patients with malignant ascites. Jpn J Clin Oncol 37: 930-935, 2007

6. Bouche O, Raoul JL, Bonnetain F, et al: Randomized multicenter phase II trial of a biweekly regimen of fluorouracil and leucovorin (LV5FU2), LV5FU2 plus cisplatin, or LV5FU2 plus irinotecan in patients with previously untreated metastatic gastric cancer: a Federation Francophone de Cancerologie Digestive Group Study - FFCD 9803. J Clin Oncol 22: 4319-4328, 2004.

7. Kim SG, Oh SY, Kwon HC, et al: A phase II study of irinotecan with bi-weekly, low-dose leucovorin and bolus and continuous infusion 5-fluorouracil (modified FOLFIRI) as salvage therapy for patients with advanced or metastatic gastric cancer. Jpn J Clin Oncol 37: 744-749, 2007.

8. Metzger R, Leichman CG, Danenberg KD, et al: ERCC1 mRNA levels complement thymidylate synthase mRNA levels in predicting response and survival for gastric cancer patients receiving combination cisplatin and fluorouracil chemotherapy. J Clin Oncol 16: 309-316, 1998.

9. Shirota Y, Stoehlmacher J, Brabender J, et al: ERCC1 and thymidylate synthase mRNA levels predict survival for colorectal cancer patients receiving combination oxaliplatin and fluorouracil chemotherapy. J Clin Oncol 19: 4298-4304, 2001.
10. Park DJ, Stoehlmacher J, Zhang W, Tsao-Wei DD, Groshen S and Lenz HJ: A Xeroderma pigmentosum group D gene polymorphism predicts clinical outcome to platinum-based chemotherapy in patients with advanced colorectal cancer. Cancer Res 61: 8654-8658, 2001

11. Gurubhagavatula S, Liu G, Park S, et al: XPD and XRCC1 genetic polymorphisms are prognostic factors in advanced nonsmall cell lung cancer patients treated with platinum chemotherapy. J Clin Oncol 22: 2594-2601, 2004.

12. Suk R, Gurubhagavatula S, Park S, et al: Polymorphisms in ERCC1 and grade 3 or 4 toxicity in non-small cell lung cancer patients. Clin Cancer Res 11: 1534-1538, 2005.

13. Goekkurt E, Hoehn S, Wolschke C, et al: Polymorphisms of glutathione S-transferases (GST) and thymidylate synthase (TS) - novel predictors for response and survival in gastric cancer patients. Br J Cancer 94: 281-286, 2006.

14. Ruzzo A, Graziano F, Kawakami K, et al: Pharmacogenetic profiling and clinical outcome of patients with advanced gastric cancer treated with palliative chemotherapy. J Clin Oncol 24: 1883-1891, 2006.

15. Mathijssen RH, van Alphen RJ, Verweij J, et al: Clinical pharmacokinetics and metabolism of irinotecan (CPT-11). Clin Cancer Res 7: 2182-2194, 2001.

16. Humerickhouse R, Lohrbach K, Li L, Bosron WF and Dolan ME: Characterization of CPT-11 hydrolysis by human liver carboxylesterase isoforms hCE-1 and hCE-2. Cancer Res 60: 1189-1192, 2000.

17. Hua D, Huang ZH, Mao Y and Deng JZ: Thymidylate synthase and thymidine phosphorylase gene expression as predictive parameters for the efficacy of 5-fluorouracil-based adjuvant chemotherapy for gastric cancer. World J Gastroenterol 13: 5030-5034, 2007

18. Wei J, Zou Z, Qian X, et al: ERCC1 mRNA levels and survival of advanced gastric cancer patients treated with a modified FOLFOX regimen. Br J Cancer 98: 1398-1402, 2008.

19. Kawakami K, Omura K, Kanehira E and Watanabe Y: Polymorphic tandem repeats in the thymidylate synthase gene is associated with its protein expression in human gastrointestinal cancers. Anticancer Res 19: 3249-3252, 1999.

20. Kawakami K, Salonga D, Park JM, et al: Different lengths of a polymorphic repeat sequence in the thymidylate synthase gene affect translational efficiency but not its gene expression. Clin Cancer Res 7: 4096-4101, 2001

21. Mandola MV, Stoehlmacher J, Zhang W, et al: A 6 bp polymorphism in the thymidylate synthase gene causes message instability and is associated with decreased intratumoral TS mRNA levels. Pharmacogenetics 14: 319-327, 2004.

22. Therasse P, Arbuck SG, Eisenhauer EA, et al: New guidelines to evaluate the response to treatment in solid tumors. European Organization for Research and Treatment of Cancer, National Cancer Institute of the United States, National Cancer Institute of Canada. J Natl Cancer Inst 92: 205-216, 2000.

23. Huang MJ, Kua KE, Teng HC, Tang KS, Weng HW and Huang CS: Risk factors for severe hyperbilirubinemia in neonates. Pediatr Res 56: 682-689, 2004.

24. Zhou W, Gurubhagavatula S, Liu G, et al: Excision repair crosscomplementation group 1 polymorphism predicts overall survival in advanced non-small cell lung cancer patients treated with platinum-based chemotherapy. Clin Cancer Res 10: 4939-4943, 2004.

25. Harries LW, Stubbins MJ, Forman D, Howard GC and Wolf CR: Identification of genetic polymorphisms at the glutathione Stransferase Pi locus and association with susceptibility to bladder, testicular and prostate cancer. Carcinogenesis 18: 641-644, 1997.

26. Arand M, Muhlbauer R, Hengstler J, et al: A multiplex polymerase chain reaction protocol for the simultaneous analysis of the glutathione S-transferase GSTM1 and GSTT1 polymorphisms. Anal Biochem 236: 184-186, 1996.

27. Wilson MD, Ruttan CC, Koop BF and Glickman BW: ERCC1: a comparative genomic perspective. Environ Mol Mutagen 38: 209-215, 2001.

28. Dabholkar M, Bostick-Bruton F, Weber C, Bohr VA, Egwuagu C and Reed E: ERCC1 and ERCC2 expression in malignant tissues from ovarian cancer patients. J Natl Cancer Inst 84: 1512-1517, 1992.

29. Dabholkar M, Vionnet J, Bostick-Bruton F, Yu JJ and Reed E: Messenger RNA levels of XPAC and ERCC1 in ovarian cancer tissue correlate with response to platinum-based chemotherapy. J Clin Invest 94: 703-708, 1994. 
30. Park DJ, Zhang W, Stoehlmacher J, et al: ERCC1 gene polymorphism as a predictor for clinical outcome in advanced colorectal cancer patients treated with platinum-based chemotherapy. Clin Adv Hematol Oncol 1: 162-166, 2003.

31. Liu D, O'Day SJ, Yang D, et al: Impact of gene polymorphisms on clinical outcome for stage IV melanoma patients treated with biochemotherapy: an exploratory study. Clin Cancer Res 11: 1237-1246, 2005.

32. Isla D, Sarries C, Rosell R, et al: Single nucleotide polymorphisms and outcome in docetaxel-cisplatin-treated advanced non-small cell lung cancer. Ann Oncol 15: 1194-1203, 2004

33. Viguier J, Boige V, Miquel C, et al: ERCC1 codon 118 polymorphism is a predictive factor for the tumor response to oxaliplatin/5-fluorouracil combination chemotherapy in patients with advanced colorectal cancer. Clin Cancer Res 11: 6212-6217, 2005 .

34. Stoehlmacher J, Park DJ, Zhang W, et al: A multivariate analysis of genomic polymorphisms: prediction of clinical outcome to 5-FU/oxaliplatin combination chemotherapy in refractory colorectal cancer. Br J Cancer 91: 344-354, 2004.

35. Oguri T, Fujiwara Y, Katoh O, et al: Glutathione S-transferasepi gene expression and platinum drug exposure in human lung cancer. Cancer Lett 156: 93-99, 2000.

36. Stoehlmacher J, Park DJ, Zhang W, et al: Association between glutathione S-transferase P1, T1, and M1 genetic polymorphism and survival of patients with metastatic colorectal cancer. J Natl Cancer Inst 94: 936-942, 2002.

37. Hohaus S, Di Ruscio A, Di Febo A, et al: Glutathione Stransferase P1 genotype and prognosis in Hodgkin's lymphoma. Clin Cancer Res 11: 2175-2179, 2005

38. Shu XO, Gao YT, Cai Q, et al: Genetic polymorphisms in the TGF-beta 1 gene and breast cancer survival: a report from the Shanghai Breast Cancer Study. Cancer Res 64: 836-839, 2004.

39. Davies SM, Robison LL, Buckley JD, et al: Glutathione Stransferase polymorphisms and outcome of chemotherapy in childhood acute myeloid leukemia. J Clin Oncol 19: 1279-1287, 2001.

40. DeMichele A, Aplenc R, Botbyl J, et al: Drug-metabolizing enzyme polymorphisms predict clinical outcome in a nodepositive breast cancer cohort. J Clin Oncol 23: 5552-5559, 2005.
41. Sweeney C, Nazar-Stewart V, Stapleton PL, Eaton DL and Vaughan TL: Glutathione S-transferase M1, T1 and P1 polymorphisms and survival among lung cancer patients. Cancer Epidemiol Biomarkers Prev 12: 527-533, 2003.

42. Lee JM, Wu MT, Lee YC, et al: Association of GSTP1 polymorphism and survival for esophageal cancer. Clin Cancer Res 11: 4749-4753, 2005

43. Iyer L, Hall D, Das S, et al: Phenotype-genotype correlation of in vitro $\mathrm{SN}-38$ (active metabolite of irinotecan) and bilirubin glucuronidation in human liver tissue with UGT1A1 promoter polymorphism. Clin Pharmacol Ther 65: 576-582, 1999.

44. Iyer L, Das S, Janisch L, et al: UGT1A1*28 polymorphism as a determinant of irinotecan disposition and toxicity. Pharmacogenomics J 2: 43-47, 2002.

45. Tan BR and McLeod HL: Pharmacogenetic influences on treatment response and toxicity in colorectal cancer. Semin Oncol 32: 113-119, 2005

46. Han JY, Lim HS, Shin ES, et al: Comprehensive analysis of UGT1A polymorphisms predictive for pharmacokinetics and treatment outcome in patients with non-small cell lung cancer treated with irinotecan and cisplatin. J Clin Oncol 24: 2237-2244, 2006.

47. Peters GJ, Backus HH, Freemantle S, et al: Induction of thymidylate synthase as a 5-fluorouracil resistance mechanism. Biochim Biophys Acta 1587: 194-205, 2002.

48. Pullarkat ST, Stoehlmacher J, Ghaderi V, et al: Thymidylate synthase gene polymorphism determines response and toxicity of 5-FU chemotherapy. Pharmacogenomics J 1: 65-70, 2001.

49. Mandola MV, Stoehlmacher J, Muller-Weeks S, et al: A novel single nucleotide polymorphism within the 5 ' tandem repeat polymorphism of the thymidylate synthase gene abolishes USF-1 binding and alters transcriptional activity. Cancer Res 63: 2898-2904, 2003.

50. Marcuello E, Altes A, Del Rio E, Cesar A, Menoyo A and Baiget M: Single nucleotide polymorphism in the $5^{\prime}$ tandem repeat sequences of thymidylate synthase gene predicts for response to fluorouracil-based chemotherapy in advanced colorectal cancer patients. Int J Cancer 112: 733-737, 2004.

51. Ishida Y, Kawakami K, Tanaka Y, Kanehira E, Omura K and Watanabe G: Association of thymidylate synthase gene polymorphism with its mRNA and protein expression and with prognosis in gastric cancer. Anticancer Res 22: 2805-2809, 2002. 